\title{
Does Skeletal Muscle Loss and Sarcopenia Predispose Patients for the Development of a Paraconduit Hernia After Minimally Invasive Esophagectomy? - A Propensity Matched Case- control Study
}

Henriikka Hietaniemi

Helsinki University Hospital

Tommi Järvinen ( $\nabla$ tommi.jarvinen@hus.fi )

Helsinki University Hospital

Illkka llonen

Helsinki University Hospital

Jari Räsänen

Helsinki University Hospital

\section{Research Article}

Keywords: Paraconduit hernia, Esophagectomy, sarcopenia

Posted Date: January 31st, 2022

DOI: https://doi.org/10.21203/rs.3.rs-1211541/v1

License: (9) This work is licensed under a Creative Commons Attribution 4.0 International License. Read Full License 


\section{Abstract}

\section{Background}

Paraconduit hernia is a relatively common long-term complication after esophagectomy which has the potential to cause great morbidity and even mortality. The aim of this study is to examine the relationship between sarcopenia and muscle mass loss and paraconduit hernia after minimally invasive esophagectomy in esophageal adenocarcinoma patients who have received neoadjuvant treatment.

\section{Methods}

All minimally invasive esophagectomies done for patients with neoadjuvant-treated esophageal or esophagogastric junction adenocarcinoma at our institution between 2008 and 2018 were included in this study. Propensity score matching was utilized to minimize confounding effects of retrospective data analysis. Computed tomography scans were used to measure skeletal muscle mass and to quantify sarcopenia.

\section{Results}

The incidence of paraconduit hernia was 14 out of 171 patients (8.2\%). The hernia was surgically repaired in $10(71.4 \%)$ of patients. A total of $23(82.1 \%)$ patients in the matched group were sarcopenic before start of neoadjuvant treatments, 22 (78.6\%) after neoadjuvant treatments and $24(85.7 \%)$ at 6 months of follow-up. Skeletal muscle area, skeletal muscle index or prevalence of sarcopenia had no correlation with paraconduit hernia developement. Using the median change of skeletal muscle area between pre-neoadjuvant and 6 months follow-up visit as a threshold to divide the patients into two equal size groups yielded no significantly different survival curves using Kaplan-Meier analysis $(p=0.6)$.

\section{Conclusion}

Paraconduit hernia is a relatively common complication after minimally invasive esophagectomy for neadjuvantly treated adenocarcinoma patients. Sarcopenia and muscle mass loss are not predictive factors for paraconduit hernia.

\section{Introduction}

The incidence of esophageal adenocarcinoma is increasing in many Western countries. ${ }^{1,2}$

Esophagectomy is the only curative treatment in advanced disease, but it is associated with a high rate of perioperative complications. ${ }^{3-5}$ With current multimodality treatments and advanced staging methods, the 5-year survival of surgically treated esophageal adenocarcinoma has improved significantly. 3,6,7 Minimally invasive esophagectomy (MIE) has been established as a safe approach to treat esophageal cancer and is associated with less pulmonary complications and postoperative pain than open 
esophagectomy (OE). ${ }^{3}$ However, the incidence of paraconduit hernia after MIE has been higher than after OE. ${ }^{3,8-12}$

Paraconduit hernia after esophagectomy is a rare but notable late-onset postoperative complication. It occurs when intraperitoneal contents, such as small or large bowel, herniate through the hiatal orifice and accounts for considerable morbidity due to life threatening emergencies with incarceration, strangulation and perforation of the bowel. ${ }^{9,13,14}$ With prolonged life expectancy, an increasing number of patients suffering from paraconduit hernia will potentially need treatment in the future. A recent review found the rate of paraconduit hernia after MIE to be $4.5 \%$ and $1.0 \%$ after open esophagectomy (OE), incidence rates ranging between $0-26 \%$ after MIE and $0-10 \%$ after $\mathrm{OE} .{ }^{15}$ Treating paraconduit hernias by minimially invasive approach has been gaining traction and seems to be safe. ${ }^{8,13,16}$

In the recent years, there have been numerous studies on sarcopenia, and other markers of frailty, as prognostic factors in cancers. Sarcopenia is defined as the progressive loss of muscle related to aging or disease. ${ }^{17}$ Sarcopenia, and loss of muscle mass have been associated with worse outcomes in esophageal and esophagogastric junction cancer. ${ }^{18-20}$ Pronounced loss of muscle mass during neoadjuvant treatments has also been indicated in poor prognosis of esophageal cancer. ${ }^{20}$

The aim of this trial was to explore the effects of sarcopenia and muscle loss on the development of paraconduit hernia, as well as to explore other risk factors for paraconduit hernia development. As the link between muscle loss during neoadjuvant treatments and survival has been previously established, we postulated that the same effect could also be seen in paraconduit hernia development. To avoid unnecessary heterogeneity related to different neoadjuvant treatments and tumor location, only patients with adenocarcinoma of the esophagus or esophagogastric junction were examined.

\section{Methods}

This is a retrospective consecutive case-series of paraconduit hernia after MIE from 2008 to 2018. Only patients with esophageal or esophagogastric junction adenocarcinoma were included. This was done to minimize the confounding brought by esophageal squamous cell cancer patients, whose operation types, comorbidities and neoadjuvant treatments are different. The primary endpoint was the development of paraconduit hernia.

\section{Data acquisition}

The data was collected from the electronic medical records, after a minimum of two-year follow up after MIE. Information collected included patient age, sex, BMI, tumor characteristics, neoadjuvant- and adjuvant treatment details, co-morbidities, and symptoms. The operation reports of both the primary esophagectomy and hernia repair were studied for technical details. Follow-up reports and surveillance imaging were investigated for treatment outcomes including complications, mortality, readmissions, 
reoperations and hernia recurrence. The complications were graded retrospectively according to the Clavien-Dindo classification. ${ }^{21}$

\section{Neoadjuvant treatment}

In our institution, patients with cT2-4 \& N0-2 esophageal adenocarcinoma are considered for neoadjuvant therapy in a multidisciplinary meeting. The neoadjuvant regimen used is FLOT (docetaxel, oxaliplatin, fluorouracil, and leucovorin), however other regimens can be recommended based on patient factors. ${ }^{22}$

\section{Surgical treatment}

Minimally invasive and open Ivor Lewis and McKeown esophagectomies are performed in our center. ${ }^{23-}$

${ }^{25}$ In Ivor Lewis reconstruction we use a $4 \mathrm{~cm}$ wide gastric conduit pulled up to the thoracic cavity and anastomosed approximately at the level of the azygos vein. In general, at the end of the laparoscopic procedure the conduit is fixed with sutures to the diaphragmatic crura. If the hiatal opening appears wide, it is loosely closed after the conduit is placed in left thoracic cavity during the laparoscopic portion of the operation.

Our approach to paraconduit hernia repair is a 4-5 port laparoscopic repair, in which, the hernia contents are mobilized completely and reduced back to abdomen. The possible hernia sac is excised, and the hiatus is closed with non-absorbable sutures and if needed, reinforced with mesh. The conduit is then refixed to the crura with sutures. Laparotomy and/or thoracotomy incisions are used if minimally invasive repair is not feasible.

\section{Follow-up}

Patients undergo a surveillance program within our institution for up to five years postoperatively. The follow-up for esophageal cancer includes outpatient appointments at 1, 3, 6, 12, and 18 months and then annually from 2 to 5 years, including CT scans at 6 months, 18 months, and 2, 3, 4 and 5 years postoperatively. A gastroscopy is performed at 3 months, 1 year, 2 years and 4 years post operatively.

\section{Measurement of muscle parameters \& sarcopenia definition}

Esophageal cancer patients undergo a full body CT scan before the start of neoadjuvant therapy, after completion of neoadjuvant therapy and at 6 months after surgery. These scans were used to measure muscle mass and define sarcopenia before neoadjuvant treatments, before surgery and at 6 months of follow-up respectively. Scans were coded in order to blind the researchers from outcome. Images were imported to Osirix ${ }^{\circledR}$ Version 12.0 (32-bit Pixmeo, Sarl, Switzerland). Abdominal musculature was delineated by use of a semi-automatic selection of region of interest tool from the level of L3. Psoas, quadratus lumborum, paraspinal, transverse abdominal, external oblique, internal oblique, and rectus abdominis muscles were included. The Hounsfield Unit threshold range for skeletal muscle was -29 to +150. The images were manually corrected, if needed, by the propulsion and brush tools in Osirix $\odot$. The cross-sectional total muscle area at the level of L3, Skeletal muscle area (SMA; unit: $\mathrm{cm} 2$ ) was divided by the square of height (m2), which produced the Skeletal Muscle Index (SMI). This method is suggested as 
the preferred method of measuring the muscle mass of cancer patients. ${ }^{26} \mathrm{SMI}$ limit for sarcopenia was < $52.4 \mathrm{~cm} 2 / \mathrm{m} 2$ for men and $<38,538.5 \mathrm{~cm} 2 / \mathrm{m} 2$ for women, based on a previous study by Prado et al. ${ }^{27}$

\section{Statistics}

The data was analyzed with R project (R Core Team (2020). R: A language and environment for statistical computing. R Foundation for Statistical Computing, Vienna, Austria. URL https://www.R-project.org/). The risk factors for hernia were calculated using binary logistic regression. Correlation to complications with categorical variables was done by $\chi^{2}$, or Fisher's exact test and with numerical variables with binary logistic regression.

We propensity matched patients with paraconduit hernia 1:1 to a control group without a paraconduit hernia. We calculated the propensity scores using generalized linear model with age, sex, preoperative stent insertion, preoperative radiotherapy, graft saturation to crura and major postoperative complications as the dependent covariables. We performed propensity score matching with R package "Matchlt" by nearest propensity score method. ${ }^{28}$ We calculated standardised differences between the unmatched SEMS insertion group and the control group and compared them to the standardised differences of the matched groups. We then performed statistical analysis on the newly formed case cohort to identify any statistically significant differences between the groups.

The study was approved by the Helsinki University Institutional Review Board (IRB) as part of the rare hernias study (HUS/60/2019).

\section{Results}

A total of 466 esophagectomies for esophageal cancer were performed in our center between 2008 and 2018. Of these, 335 cases were operated with MIE and 131 OE approach. Of these patients, 171 had adenocarcinoma of the esopahgus or gastroesophageal junction, underwent neoadjuvant treatment and were operated on with MIE. Of these patients, $5.9 \%(n=10)$ went through chemoradiotherapy with paclitaxel and carboplatin, $93.6 \%$ chemotherapy alone $(n=160)$ and $0.6 \%(n=1)$ radiotherapy alone. The most used regimen for chemotherapy was 3 rounds of EOX (epirubicin, oxaliplatin, capecitabin; $n=116$, $67.8 \%$ ). Other regimens included XELOX (oxaliplatin and capecitabin; $4.1 \%, n=7$ ), FLOT (fluorouracil, leucovorin, oxaliplatin and docetaxel; $2.9 \%, n=5)$, SOX (S-1 and oxaliplatin; $0.6 \%, n=1$ ) and FOLFOX (folinic acid, fluorouracil, and oxaliplatin; $0.6 \%, \mathrm{~N}=1$ ). The used regimen was not specified in $17.5 \%$ $(n=30)$.

Paraconduit hernia was found in 14 (8,2\%) patients after MIE for esophageal adenocarcinoma, the median time from operation to the diagnosis of paraconduit hernia was 17 months (range 0-113 months). (Table 1). At 3 years the incidence of paraconduit hernia in the surviving patients was $11.4 \%$ and at 5 years $13.6 \%$. The cumulative hazard of paraconduit hernia after minimally invasive esophagectomy for esophageal and esophagogastric junction adenocarcinoma is shown in Figure 1. 
Table 1

Demographics of patients who underwent MIE after neoadjuvant treatment for esophageal and esophagogastric junction adenocarcinoma

\begin{tabular}{|c|c|c|c|}
\hline & & All & Paraconduit hernia \\
\hline & & $\mathrm{n}(\%)$ & \\
\hline Sex & Female & $32(18.7)$ & $1(7.1)$ \\
\hline & Male & 139 (81.3) & $13(92.9)$ \\
\hline Age & mean $(S D)$ & $63.8(9.4)$ & $64.3(9.4)$ \\
\hline BMI & mean $(S D)$ & $25.3(4.8)$ & $22.2(2.9)$ \\
\hline ECOG & 0 & $122(71.3)$ & $11(78.6)$ \\
\hline & 1 & $48(28.1)$ & $3(21.4)$ \\
\hline Location & Middle esophagus & $2(1.2)$ & $0(0)$ \\
\hline & Distal esophagus & 57 (33.3) & $4(28.6)$ \\
\hline & GE-juction/cardia & $112(65.5)$ & $10(71.4)$ \\
\hline Preoperative treatment & Chemotherapy & $160(93.6)$ & $10(71.4)$ \\
\hline & Chemoradiotherapy & $10(5.8)$ & $3(21.4)$ \\
\hline & Radiotherapy & $1(0.6)$ & $1(7.1)$ \\
\hline Operation type & Ivor Lewis & $166(97.1)$ & $13(92.9)$ \\
\hline & McKeown & $3(1.8)$ & $1(7.1)$ \\
\hline & Transhiatal & $1(0.6)$ & $0(0)$ \\
\hline & Roux-en-Y & $1(0.6)$ & $0(0)$ \\
\hline Approach & MIE & $160(93.6)$ & $14(100)$ \\
\hline & Hybrid & $10(5.8)$ & $0(0)$ \\
\hline & Laparoscopic transhiatal & $1(0.6)$ & $0(0)$ \\
\hline Conversion & & $15(8.8)$ & $0(0)$ \\
\hline Major complication & & $44(25.7)$ & $2(14.3)$ \\
\hline Lymph nodes & mean (SD) & $20.7(10.3)$ & $20.5(8.7)$ \\
\hline Preoperative hernia & & $37(21.6)$ & $1(2.7)$ \\
\hline Preoperative esophagus & $52(30.4)$ & & \\
\hline
\end{tabular}


The paraconduit hernia was operatively repaired in $71 \%$ of cases $(n=10)$. The overall rate of paraconduit hernia requiring operative repair in the study population was $5.8 \%$. The median time from esophagectomy to hernia repair was 14 months (range 0-113 months). Laparoscopic approach was used in $90 \%(n=9)$ of the hernia repairs, and $30 \%(n=3)$ were operated on in urgent or emergent basis. The median operating time was 100 minutes (SD = 52 minutes). The details related to paraconduit repairs can be appreciated in Table 2 . There was one (10\%) mortality after repair of paraconduit hernia. The patient in question had peritoneal tumor implants and presented with a week of symptoms from acute small bowel obstruction. Laparotomy was performed a in a life-threatening situation with vital indication. The patient suffered from multiple organ failure and died on postoperative day 8.

Table 2

Characteristics of paraconduit hernia repair operations

\begin{tabular}{|llll|}
\hline & & $\mathbf{n}$ & $\mathbf{( \% )}$ \\
\hline Time from primary operation & $<90$ days & 1 & $(10.0)$ \\
\hline & $90-365$ days & 2 & $(20.0)$ \\
\hline Symptomatic & $>365$ days & 7 & $(70.0)$ \\
\hline Technique & & 5 & $(50.0)$ \\
\hline & Laparoscopy & 9 & $(90.0)$ \\
\hline Urgency & Conversion & 1 & $(11.1)$ \\
\hline Repair & Laparotomy & 1 & $(10.0)$ \\
\hline & Elective & 7 & $(70.0)$ \\
\hline Emergency & 3 & $(30.0)$ \\
\hline Bowel resection & Hiatoplasty and fixation & 4 & $(40.0)$ \\
\hline Hernia Type & Hiatoplasty & 1 & $(10.0)$ \\
\hline & Fixation of graft & 1 & $(10.0)$ \\
\hline Mesh & 4 & $(40.0)$ \\
\hline & Colon & 7 & $(70.0)$ \\
\hline Small bowel & 2 & $(20.0)$ \\
\hline Colon and small bowel & 1 & $(10.0)$ \\
\hline & & 1 & $(0.0)$ \\
\hline & & 1 & $(10.0)$ \\
\hline
\end{tabular}


Using multivariate binomial logistic regression model, preoperative radiotherapy $(\mathrm{OR}=9.62 ; 95 \% \mathrm{Cl}=$ 1.33-71.46, $\mathrm{p}=0.0220)$ and a BMI less than $25(\mathrm{OR}=9.59,95 \% \mathrm{Cl}=1.48-194.26, \mathrm{p}=0.0464)$ were found to be strong risk factors for paraconduit hernia development in the unmatched group, as shown in Table 3.

Table 3

Risk factors for paraconduit hernia, unmatched group

\begin{tabular}{|llll|}
\hline & OR & $95 \% \mathrm{Cl}$ & $\boldsymbol{p}$ \\
\hline Age & 0.96 & $0.89-1.04$ & 0.2965 \\
\hline Male sex & 0.56 & $0.03-4.08$ & 0.6218 \\
\hline BMl under 25 & 9.59 & $1.48-194.26$ & 0.0464 \\
\hline Major Complication & 0.45 & $0.06-2.28$ & 0.3813 \\
\hline Preoperative stent & 2.56 & $0.58-12.77$ & 0.2240 \\
\hline Conduit sutured to crura & 0.34 & $0.04-3.05$ & 0.2878 \\
\hline Preoperative radiotherapy & 9.62 & $1.33-71.46$ & 0.0220 \\
\hline
\end{tabular}

Total of 14 patients without paraconduit hernia were propensity matched with the paraconduit hernia group $(\mathrm{N}=14)$. The demographics of the propensity score matched groups can be seen in Table 4 and the Love plot of standardized mean differences of covariates in Figure 2. All of the covariates showed improved balance after matching, although some of the covariates still had residual differences, as shown by the SMD values $>0.1$ in Figure 2 . The measured skeletal muscle parameters for both of these groups can be seen in Table 5. A total of $23(82.1 \%)$ patients in the matched group were sarcopenic before start of neoadjuvant treatments, $22(78.6 \%)$ after neoadjuvant treatments and $24(85.7 \%)$ at 6 months of follow-up. None of the skeletal muscle parameters were statistically significantly different between the groups. We then used median change of skeletal muscle area ( $\triangle S M A)$ between preneoadjuvant and 6 months follow-up visit to divide the patients into two equal size groups. With these groups, a Kaplan-Meier survival analysis of freedom from hernia was done, shown in Figure 3 . This yielded no statistically significant difference between the groups $(p=0.6)$. 


\begin{tabular}{|c|c|c|c|c|}
\hline \multicolumn{5}{|c|}{ Table 4 Demographics of the propensity matched groups } \\
\hline & \multicolumn{2}{|c|}{ Paraconduit Hernia } & \multicolumn{2}{|c|}{ No paraconduit hernia } \\
\hline & \multicolumn{2}{|c|}{$(N=14)$} & \multicolumn{2}{|c|}{$(N=14)$} \\
\hline \multicolumn{5}{|l|}{ Age (Years) } \\
\hline Mean (SD) & 64.3 & $(9.44)$ & 63.8 & $(8.48)$ \\
\hline \multicolumn{5}{|l|}{ Sex } \\
\hline Male & 13 & $(92.9 \%)$ & 14 & $(100.0 \%)$ \\
\hline Female & 1 & $(7.1 \%)$ & 0 & $(0 \%)$ \\
\hline Major Complications & 12 & $(85.7 \%)$ & 11 & $(78.6 \%)$ \\
\hline Preoperative stent & 7 & $(50.0 \%)$ & 7 & $(50.0 \%)$ \\
\hline Conduit fixation & 3 & $(21.4 \%)$ & 2 & $(14.3 \%)$ \\
\hline Preoperative radiotherapy & 10 & $(71.4 \%)$ & 10 & $(71.4 \%)$ \\
\hline
\end{tabular}


Table 5

Muscle measurements between patients with paraconduit hernia and no paraconduit hernia

\begin{tabular}{|c|c|c|c|c|c|}
\hline & \multicolumn{2}{|c|}{ Paraconduit hernia } & \multicolumn{2}{|c|}{ No paraconduit hernia } & $p$ \\
\hline & \multicolumn{2}{|c|}{$(N=14)$} & \multicolumn{2}{|c|}{$(N=14)$} & \\
\hline \multicolumn{6}{|l|}{ Preneoadjuvant } \\
\hline SMA, mean (SD) & 138 & $(25)$ & 142 & (34) & 0.722 \\
\hline SMI, mean (SD) & 42 & (7) & 46 & (9) & 0.301 \\
\hline Sarcopenia, N (\%) & 12 & $(85.7)$ & 11 & $(78.6)$ & 1.000 \\
\hline \multicolumn{6}{|l|}{ Preoperative } \\
\hline SMA, mean (SD) & 131 & $(25)$ & 130 & (31) & 0.958 \\
\hline SMI, mean (SD) & 41 & (8) & 42 & (8) & 0.801 \\
\hline Sarcopenia, N (\%) & 12 & $(85.7)$ & 10 & $(71.4)$ & 0.645 \\
\hline \multicolumn{6}{|l|}{6 months follow-up } \\
\hline SMA, mean (SD) & 132 & $(24)$ & 131 & (31) & 0.884 \\
\hline SMI, mean (SD) & 42 & (6) & 42 & (9) & 0.915 \\
\hline Sarcopenia, N (\%) & 13 & $(92.9)$ & 11 & $(78.6)$ & 0.589 \\
\hline Preoperative BMI, mean (SD) & 22 & (4) & 21 & (3) & 0.624 \\
\hline \multicolumn{6}{|c|}{$\mathrm{SMA}=$ Skeletal muscle area at the level of $\mathrm{L} 3, \mathrm{unit}=\mathrm{cm} 2$} \\
\hline \multicolumn{6}{|c|}{ SMI = Skeletal muscle index i.e. SMA standardized to patients height, unit $=\mathrm{cm} 2 / \mathrm{m} 2$} \\
\hline $\mathrm{BMI}=$ Body mass index, unit & & & & & \\
\hline
\end{tabular}

\section{Discussion}

Paraconduit hernia is a relatively common long-term complication after esophagectomy for distal esophageal and gastroesophageal junction adenocarcinoma with an incidence of $8.1 \%$. It can be repaired safely with laparoscopic approach in experienced centers, with a complication rate of $10 \%$ in our series. Neither sarcopenia nor muscle loss during treatments was correlated with paraconduit hernia formation in our series.

Patients with or without paraconduit hernia did not have differing skeletal muscle measurements before neoadjuvant treaments, preoperatively or after 6 months of follow-up, as seen in Table 5. Kaplan-Meier survival curves did not differ between the group who had less pronounced muscle loss between preneoadjuvant state and 6 months follow-up compared to those who had pronounced muscle loss during this time period. These results indicate that sarcopenia or progressing muscle loss are not related 
to paraconduit hernia formation. To our knowledge, this study is the first to examine this relationship. Previous studies have, however established a strong link with loss of muscle mass during neoadjuvant treatments, sarcopenia in general, and worsened overall survival. ${ }^{18-20}$

Preoperative radiotherapy was linked to a higher risk of paraconduit hernia, as has been seen in previous studies, which is logical as the effects radiation most likely weaken the crura and the crural repairs. ${ }^{12} \mathrm{~A}$ BMI under 25 was also associated with increased risk of paraconduit hernia, however this effect was not apparent after matching (Table 5), suggesting confounding variables to be responsible for this effect. Other factors, including hiatal hernia at the time of esophagectomy or stenting before esophagectomy were not associated with paraconduit hernia.

In our study, the incidence of paraconduit hernia (8.1\%) is in line with previous reports. ${ }^{3,8}$ Rate of paraconduit hernia repair after MIE for esophageal or esophagogastric junction adenocarcinoma was $5.8 \%$, which is also similar to earlier reports. ${ }^{3,8,13}$ Laparoscopic repair was used in $90 \%$ of paraconduit hernia repair. Only one conversion to laparotomy was necessary, and this patient had peritoneal carcinosis and was in extremis from small bowel obstruction. Apart from the single patient whose prognosis was very grim related to the carcinomatosis of the peritoneal space, there were no mortality or complications related to the hernia repairs. In previous review by Oor et al, the pooled morbidity rate was $25 \%$ (range: $0 \%-60 \%) .{ }^{15}$

The majority $(71.4 \%, \mathrm{~N}=10)$ of the paraconduit hernias in this study were diagnosed more than one year after the esophagectomy, and only one case within 3 months. To prevent early paraconduit hernia in our institution, the graft is sutured to the crura in addition to a hiatoplasty as needed. We believe that this prevents paraconduit hernia formation in the immediate postoperative period. However, no comparative data on the effect of this maneuver exists. In previous studies, the hernias that appeared early after esophagectomy were associated with high morbidity. ${ }^{29}$

The strength of this study was that even though it is a retrospective study, there was good follow-up data available due to standard follow-up protocols after esophagectomy for esophageal cancer. We also utilized propensity matching to somewhat diminish the potential biases that a retrospective study design inherently contains. Additionally, Finland has a centralized archive for medical records, so that data on complications can be achieved even if they are treated at another institution.

However, there are some limitations. There is a chance for selection and information bias. As esophageal cancer is a disease with high mortality, there is considerable mortality in follow-up. We included only patients with adenocarcinoma of the distal esophagus and gastroesophageal junction, who had received neoadjuvant therapy in order to maximize homogeneity. This means the results can not automatically be generalized to all esophagectomy patients.

According to our study, paraconduit hernia is a relatively common complication in patients undergoing minimally invasive esophagectomy for esophageal- or esophagogastric junction cancer after 
neoadjuvant treatments. However, no association between paraconduit hernia formation and sarcopenia or muscle mass loss during neoadjuvant treatments could be established.

\section{Declarations}

\section{Ethics approval and Consent to Participate}

all methods were carried out in accordance with relevant guidelines and regulations. All experimental protocols were approved was approved by the Helsinki University Hospital study committee. As a retrospective study without individual level data published, ethics committee approval and informed consent was waived by Helsinki University Hospital study review board.

\section{Consent for publication}

Not applicable.

\section{Availability of data and materials}

The datasets generated and/or analysed during the current study are not publicly available due to involvement of data that makes identification of patients possible but are available in an anonymized form from the corresponding author on reasonable request.

\section{Competing interests}

The authors declare that they have no competing interests

\section{Funding}

No external funding was received for this study

\section{Authors' contributions}

$\mathrm{HH}$ and TJ collected and analyzed the data, performed statistical testing, wrote the initial manuscript and the revisions. TJ, II and JR revised and commented on the manuscript. All authors read, commented on, and approved the final manuscript.

\section{References}

1. Arnold M, Soerjomataram I, Ferlay J, Forman D. Global incidence of oesophageal cancer by histological subtype in 2012. Gut. Mar 2015;64(3):381-7. doi:10.1136/gutjnl-2014-308124 
2. Ferlay J, Steliarova-Foucher E, Lortet-Tieulent $\mathrm{J}$, et al. Cancer incidence and mortality patterns in Europe: estimates for 40 countries in 2012. Eur J Cancer. Apr 2013;49(6):1374-403. doi:10.1016/j.ejca.2012.12.027

3. Biere SS, van Berge Henegouwen MI, Maas KW, et al. Minimally invasive versus open oesophagectomy for patients with oesophageal cancer: a multicentre, open-label, randomised controlled trial. Lancet. May 19 2012;379(9829):1887-92. doi:10.1016/S0140-6736(12)60516-9

4. Scheepers JJ, Mulder CJ, Van Der Peet DL, Meijer S, Cuesta MA. Minimally invasive oesophageal resection for distal oesophageal cancer: a review of the literature. Scand J Gastroenterol Suppl. 2006;(243):123-34. doi:10.1080/00365520600664425

5. Enzinger PC, Mayer RJ. Esophageal cancer. N Engl J Med. Dec 4 2003;349(23):2241-52. doi:10.1056/NEJMra035010

6. Aad G, Abbott B, Abdallah J, et al. Measurements of the Total and Differential Higgs Boson Production Cross Sections Combining the $\mathrm{H}->$ gammagamma and $\mathrm{H}->\mathrm{ZZ}^{\wedge}\left\{{ }^{*}\right\}->4 \mid$ Decay Channels at sqrt[s]=8 TeV with the ATLAS Detector. Phys Rev Lett. Aug 28 2015;115(9):091801. doi:10.1103/PhysRevLett.115.091801

7. Shapiro J, van Lanschot JJB, Hulshof M, et al. Neoadjuvant chemoradiotherapy plus surgery versus surgery alone for oesophageal or junctional cancer (CROSS): Iong-term results of a randomised controlled trial. Lancet Oncol. Sep 2015;16(9):1090-1098. doi:10.1016/S1470-2045(15)00040-6

8. Gooszen JAH, Slaman AE, van Dieren S, Gisbertz SS, van Berge Henegouwen MI. Incidence and Treatment of Symptomatic Diaphragmatic Hernia After Esophagectomy for Cancer. Ann Thorac Surg. Jul 2018;106(1):199-206. doi:10.1016/j.athoracsur.2018.02.034

9. Matthews J, Bhanderi S, Mitchell $\mathrm{H}$, et al. Diaphragmatic herniation following esophagogastric resectional surgery: an increasing problem with minimally invasive techniques?: Post-operative diaphragmatic hernias. Surg Endosc. Dec 2016;30(12):5419-5427. doi:10.1007/s00464-016-4899-5

10. Bronson NW, Luna RA, Hunter JG, Dolan JP. The incidence of hiatal hernia after minimally invasive esophagectomy. J Gastrointest Surg. May 2014;18(5):889-93. doi:10.1007/s11605-014-2481-9

11. Crespin OM, Farjah F, Cuevas C, et al. Hiatal Herniation After Transhiatal Esophagectomy: an Underreported Complication. J Gastrointest Surg. Feb 2016;20(2):231-6. doi:10.1007/s11605-0153033-7

12. Lung K, Carroll PA, Rogalla P, Yeung J, Darling G. Paraconduit Hernia in the Era of Minimally Invasive Esophagectomy: Underdiagnosed? Ann Thorac Surg. 06 2021;111(6):1812-1819. doi:10.1016/j.athoracsur.2020.07.047

13. Ulloa Severino B, Fuks D, Christidis C, Denet C, Gayet B, Perniceni T. Laparoscopic repair of hiatal hernia after minimally invasive esophagectomy. Surg Endosc. Mar 2016;30(3):1068-72. doi:10.1007/s00464-015-4299-2

14. Price TN, Allen MS, Nichols FC, 3rd, et al. Hiatal hernia after esophagectomy: analysis of 2,182 esophagectomies from a single institution. Ann Thorac Surg. Dec 2011;92(6):2041-5. doi:10.1016/j.athoracsur.2011.08.013 
15. Oor JE, Wiezer MJ, Hazebroek EJ. Hiatal Hernia After Open versus Minimally Invasive Esophagectomy: A Systematic Review and Meta-analysis. Ann Surg Oncol. Aug 2016;23(8):2690-8. doi:10.1245/s10434-016-5155-x

16. Lowe C, Subar D, Hall C, Kumpavat J, Decadt B, Agwunobi A. Hiatal hernias presenting as a late complication of laparoscopic-assisted cardio-oesophagectomy. Hernia. Apr 2010;14(2):211-3. doi:10.1007/s10029-009-0531-0

17. Cruz-Jentoft AJ, Baeyens JP, Bauer JM, et al. Sarcopenia: European consensus on definition and diagnosis: Report of the European Working Group on Sarcopenia in Older People. Age Ageing. Jul 2010;39(4):412-23. doi:10.1093/ageing/afq034

18. Paireder M, Asari R, Kristo I, et al. Impact of sarcopenia on outcome in patients with esophageal resection following neoadjuvant chemotherapy for esophageal cancer. Eur J Surg Oncol. Feb 2017;43(2):478-484. doi:10.1016/j.ejso.2016.11.015

19. TamandI D, Paireder M, Asari R, Baltzer PA, Schoppmann SF, Ba-Ssalamah A. Markers of sarcopenia quantified by computed tomography predict adverse long-term outcome in patients with resected oesophageal or gastro-oesophageal junction cancer. Eur Radiol. May 2016;26(5):1359-67. doi:10.1007/s00330-015-3963-1

20. Jarvinen T, llonen I, Kauppi J, Salo J, Rasanen J. Loss of skeletal muscle mass during neoadjuvant treatments correlates with worse prognosis in esophageal cancer: a retrospective cohort study. World J Surg Oncol. Feb 12 2018;16(1):27. doi:10.1186/s12957-018-1327-4

21. Clavien PA, Barkun J, de Oliveira ML, et al. The Clavien-Dindo classification of surgical complications: five-year experience. Ann Surg. Aug 2009;250(2):187-96.

doi:10.1097/SLA.0b013e3181b13ca2

22. Cunningham $D$, Allum WH, Stenning SP, et al. Perioperative chemotherapy versus surgery alone for resectable gastroesophageal cancer. New England Journal of Medicine. Jul 6 2006;355(1):11-20. doi:DOI 10.1056/NEJMoa055531

23. Lewis I. The surgical treatment of carcinoma of the oesophagus; with special reference to a new operation for growths of the middle third. Br J Surg. Jul 1946;34:18-31. doi:10.1002/bjs.18003413304

24. McKeown KC. Total three-stage oesophagectomy for cancer of the oesophagus. Br J Surg. Apr 1976;63(4):259-62. doi:10.1002/bjs. 1800630403

25. Orringer MB, Sloan H. Esophagectomy without thoracotomy. J Thorac Cardiovasc Surg. Nov 1978;76(5):643-54.

26. Fearon K, Strasser F, Anker SD, et al. Definition and classification of cancer cachexia: an international consensus. Lancet Oncol. May 2011;12(5):489-95. doi:10.1016/S1470-2045(10)70218-7

27. Prado CMM, Liefers JR, McCargar LJ, et al. Prevalence and clinical implications of sarcopenic obesity in patients with solid tumours of the respiratory and gastrointestinal tracts: a populationbased study. Lancet Oncology. Jul 2008;9(7):629-635. doi:10.1016/51470-2045(08)70153-0 
28. Ho D, Imai K, King G, Stuart EA. Matchlt: Nonparametric Preprocessing for Parametric Causal Inference. Journal of Statistical Software2011. p. 1-28.

29. Sutherland J, Banerji N, Morphew J, Johnson E, Dunn D. Postoperative incidence of incarcerated hiatal hernia and its prevention after robotic transhiatal esophagectomy. Surg Endosc. May 2011;25(5):1526-30. doi:10.1007/s00464-010-1429-8

\section{Figures}

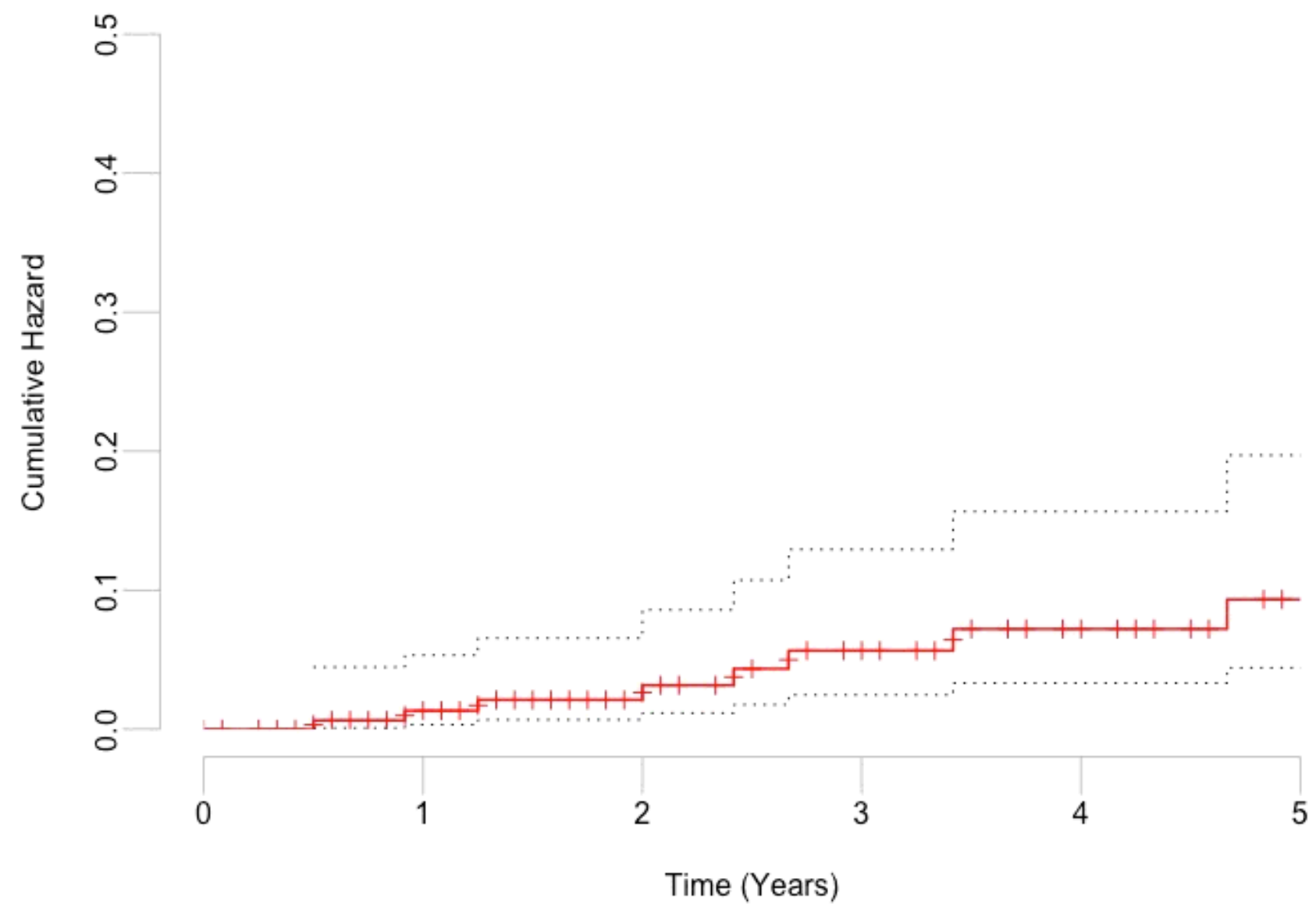

Figure 1

Cumulative hazard of paraconduit hernia after minimally invasive esophagectomy for esophageal and esophagogastric junction adenocarcinoma 
Figure 2 Covariate balance before and after matching

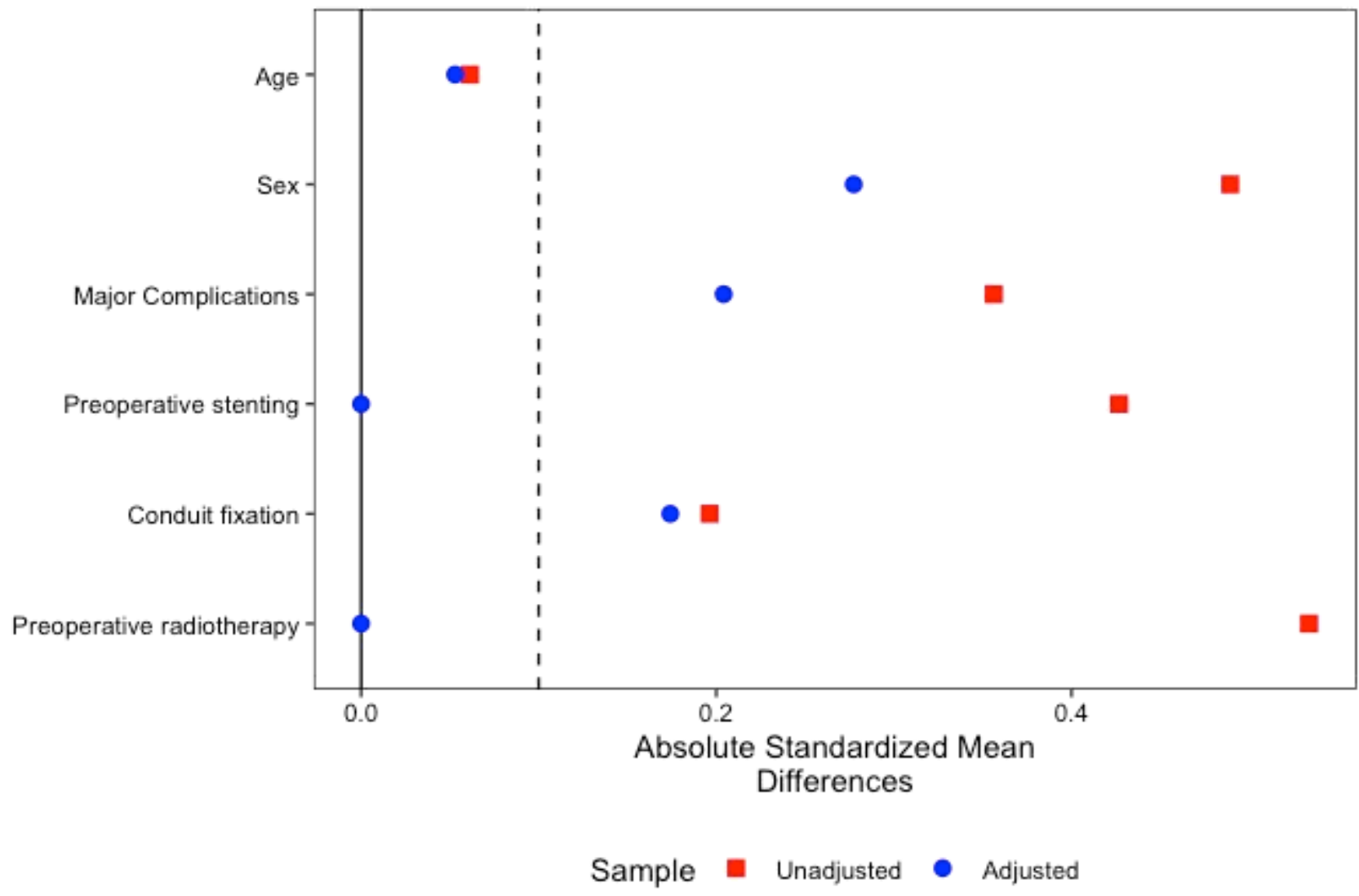

Figure 2

Love plot of standardized mean differences between patient groups with and without paraconduit hernia before propensity matching (red square) and after matching (blue circle) 
Figure 3 - Freedom from hernia based on SMA change

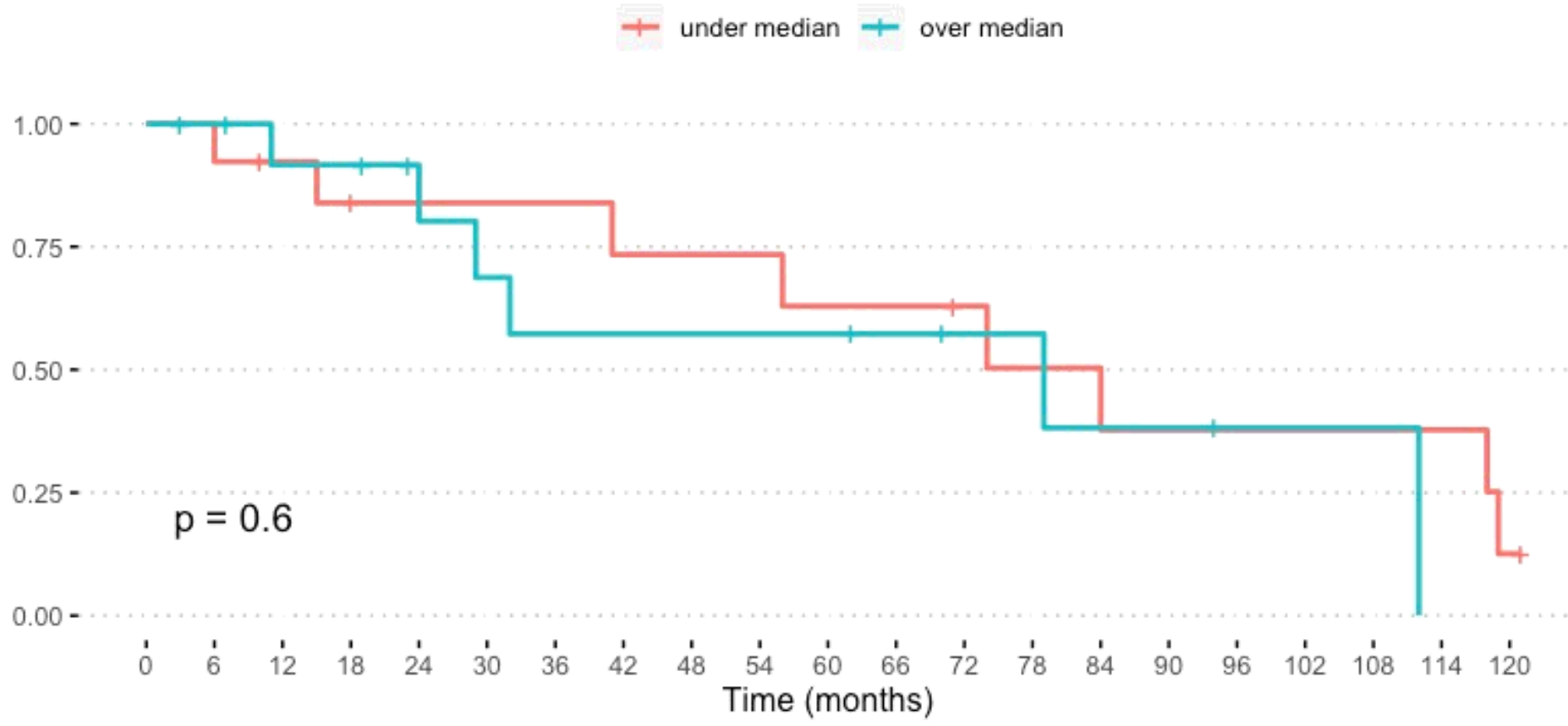

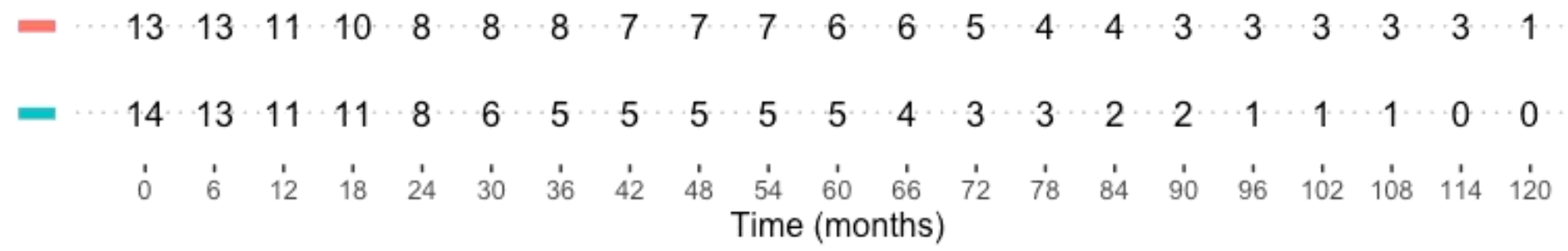

Figure 3

Kaplan-Meier survival plot of the propensity matched group, dividing the groups into two using the median of skeletal muscle change between preneoadjuvant and 6 months follow-up visit as a threshold. 